\title{
Traffic Congestion and Parking Difficulties in Akure Metropolis, Nigeria
}

\author{
Ogundare, Babatope Andrew ${ }^{1}$, Ogunbodede, Emman F (Ph.D) ${ }^{2}$ \\ ${ }^{1}$ Department of Geography, College of Education, Ikere-Ekiti, Ekiti State, Nigeria. \\ ${ }^{2}$ Department of Geography and Planning Sciences,Adekunle Ajasin University, Akungba-Akoko, \\ Ondo State, Nigeria.
}

\begin{abstract}
The city as an engine of economic development and centre of industry, commerce and administration, functions only with an efficient system of transportation. Traffic congestion is therefore one of the most predominant problems encountered in such environment of which Nigeria case is no exemption. The paper aims to describe intra-urban transport circulation in Akure metropolis with its attendant traffic congestion situation and problems. The study adopts empirical design to investigate vehicular congestion and parking difficulties in the study area. Using field observation, twelve congestion spots were identified and primary source of data was used to find out distance covered within the study area, periods when traffic holdups are experienced and time lost to traffic hold-up in a journey. The study established parking problems in the Central Business District of Akure as a major cause of traffic congestion. The paper therefore suggested that traffic flows along major roads in the city need to be monitored and controlled regularly. There is also need for parking provisions not only in the CBD but also in some identified land use zones.
\end{abstract}

\section{Introduction}

A city is a complex living system made of functioning and interesting parts. According to Ogundare (2013), different land use types are the parts and transport serves as the medium for interaction between the different land uses and people within the urban setting. In order to facilitate all activities in the city, movement must exist and therefore planning for urban transport becomes an inevitable component of the urban system.

Traffic congestion, often bad enough to require drastic control measure, was a feature of city life at least as early as Roman times (Traffic Control, 2012). A basic cause then, as now, was poor city planning, with roads laid out in such a way as to bring traffic from all quarters to a central crossing point. Congestion was severe enough in European cities in the $17^{\text {th }}$ Century to require ordinances prohibiting parking on certain streets and establishing one-way traffic. The advent of the railroad brought temporary relief to the growing problem of road traffic control, though it created congestion at terminals inside cities. The automobile, with its increase first in speed and then in numbers over horse-drawn transport, rapidly created a new situation that was to become one of the characteristic problems of urban industrialized society in the $20^{\text {th }}$ Century.

Cities and towns have been noted to be engines of growth and incubators of civilization and have facilitated the evolution of knowledge, culture and tradition as well as of industry and commerce. It is estimated that in the year 2015, fifty-five per cent of the world's population will live in urban areas. In some regions, such as Europe, North America and Latin America, over three-quarters of the population is already urban (Erguden, 1998). This situation portends great danger to traffic management in the cities as more vehicles will be on the road judging by those who will be using their private vehicles as well as those that will rely on public transport.

Moreover, congestion is still one of the most prevalent transport problems in large urban agglomerations. It is particularly linked with motorization and the diffusion of the automobiles, which has increased the demand for transport infrastructures. However, Ogunbodede et al (2008) noted that supply of infrastructures has often not been able to keep up with the growth of mobility. Increased motorization has expanded the demand for parking space hence vehicles spend precious time looking for parking lots. This situation has created space consumption problems particularly in central areas. It is important to underline, according to Rodrigue (2011) that congestion in urban areas is dominantly caused by commuting patterns and little by truck movements. On average, infrastructure provision was not able to keep up with the growth in the number of vehicles, even more with the total number of vehicles-km. On the other hand, lack of infrastructure improvement and construction, capacity impairment (fewer available lanes, closed sections, etc.) favours congestion. Important travel delays occur when the capacity limit is reached or exceeded, which is the case of almost all metropolitan areas.

Akure is a medium sized city in Nigeria where traffic congestion is one of the most noticeable problems inhibiting vehicular movement, as there are no designated parking spaces except the recent ones provided at the central and NEPA markets, which has already proved inadequate. The daily movement of people 
and goods within Akure metropolis has become more difficult and complex. The main problem therefore is that the available parking capacity could not be provided for the peak demands, and therefore waiting and delay times, which are products of traffic congestion, are inevitable prolonged.

\section{The Problem}

Nigeria is one of the countries in the developing world with rapid urbanization and fast growing cities. A study of the changing morphology of many Nigerian cities gives an insight into the evolution of urban transport problems in Nigeria. Most scholars who have worked on urban transport problems in Nigeria have identified congestion as the most serious. The problem of traffic congestion in cities of Nigeria has its roots partly in the structural pattern of the roads especially in the traditional areas of the cities and the unplanned growth and haphazard land use distribution.

However, associated with traffic congestions are problems of parking. Parking demands far outweigh the available supply in most Nigerian cities (Ogundare, 2013). This results in road-side and illegal parking, which are common features in urban centres of Nigeria. The ineffective regulation on parking has further worsened the situation. Also, since vehicles spend appreciable time looking for where to park, congestion and hold-ups therefore become a common phenomenon in the city. Unfortunately, the more parking facilities provided, the greater the demand for parking (Ogunbodede, 2004) since there is continuous increase in motorization.

The challenges facing urban centres have continued to grow particularly within the past three decades in Nigeria. Over the years, it has become the epicentre of economic and social life and has been called upon to accommodate increasingly varied activities and house a growing proportion of the population. Bailly (1998) noted that by year 2015 , more than 50 cities worldwide will be having population of over 10 million. It is this growth that is likely to create problems for traffic management if necessary steps are not taken to arrest the phenomenal growth. Today, mobility has become a strong aspiration and expression of individual freedom. As the third millennium approaches, public transport has a tough time ahead. It faces challenges on economic, social and environmental fronts in addition to the constant and powerful attraction of the private car.

\section{Aim of the Study}

The primary aim of this paper is to describe intra-urban transport circulatory system in Akure metropolis and examine its attendant traffic congestion situation as well as proffer solutions.

\section{Hypothesis}

$\mathbf{H}_{\mathbf{0}}$ : There is no relationship between valuable time lost on a journey and factors causing traffic congestion in Akure.

\section{Literature Review and Empirical Studies}

Traffic evolves because of a need to move people and goods from one location to another. As such, the movement is initiated because of decisions made by people to transport themselves or others from one location to another to participate in activities at that second location or to move goods to a location where they have higher value. The movement typically occurs along a specific facility or pathway that can be called a guide way. It may be a physical guide way, as in the case of a railroad, or it may be an agreed-upon or designated note, marked either electronically (as in aviation) or geographically (as in maritime industry). Movement-excepting pedestrian movement, which only requires human power-involves a vehicle of some type that can serve people, goods, or both.

The pattern of Nigerian urbanization has many implications on various areas of the country including determining the areas of road traffic origination and destination. Associated with these implications are various urban problems such as housing problems, environmental pollution, transportation problems and general inadequacy of infrastructural facilities (Ogunbodede, 2008). Urban mobility problems had been on the increase since independence in many Nigerian cities. This is due to rapid increase in population of urban areas, which is not matched with growth in transport facilities such as road network, transport complimentary facilities, transport services and traffic management techniques. Thus urban transport problems have increasingly been noted since 1960, to be characterized by inadequate and inefficient services, long waiting time at bus stop, long travelling time, environmental pollution, traffic congestions and bad roads, shortage of vehicles and the use of motorcycle as a means of urban passenger transport system (Ogunbodede, 2008).

Studies in the area of urban transportation confirmed that more than $75 \%$ of population in cities depended on public transport while about 25\% depended on private transport system (Ogunbodede, 1990; Ogunjumo, 1986; Mrakpor, 1986). The socio-economic variables of Nigerians contributed in no small measure to this pattern. Public transport system, which is an aspect of the country's transport sector, had all along been in 
the hands and control of Nigerian private entrepreneurs. Thus, the private owners dictated largely the modus operandi of the nation's public transport system.

The use of public transport for intra-urban movement purposes were largely concentrated in large cities like Lagos and Ibadan while commuters contend with the use of trekking within smaller towns in Nigeria as at 1960 (Ogunbodede, 2008). The situation however changed drastically today as vehicle stocks increased astronomically in towns and cities. According to Ogunsanya (1998), there were 6,822 vehicles in Nigeria by 1946 made up of 4,702 re-licensed and 2,115 new ones. The figures soared to 20,440 by 1950 made up of 14,200 re-licensed and 6,240 new ones. The vehicle stock grew gradually from this time up to 1970 when it shot up astronomically. This period coincided with the period of rapid urbanization although a period of doldrums was experienced during the period where Nigerians was engulfed in the civil war (1967-1970). After 1970, there was an automobile explosion in Nigerian cities. This is because vehicle stocks rose sharply from a modest 100,268 vehicles in 1970 to 1,009,797 in 1977 (Ogunbodede, 2008). Unfortunately, the roads constructed then were unable to accommodate the increased vehicle at such a rapid speed hence, the problem of immobility in Nigeria cities started to unfold.

\section{The Study Area}

Akure is rapidly emerging as a metropolitan city, its change from provincial headquarter to a state capital in 1976 gave the city an accelerated physical and economic growth (Aribigbola and Osunsanmi, 2010). The subsequent increase in oil revenue accruable to the state since 2003 has consequently raised the general standard of living of the citizenry (Ogunbodede, 2006).

The most noticeable of the physical expansion of the city is its population growth and urban landmass. The estimated amount of the built-up area from available land use maps have shown immense increase from $16 \mathrm{~km}^{2}$ in 1980 to about $30 \mathrm{~km}^{2}$ in 2000 . The population rose from 123,000 in 1985 to 239,124 in 1991 . The national population projection for the year 1996 and 2000 put the city population at 269,207 and 298,712 respectively. However, a sharp increase was recorded in the 2006 census, which put Akure south at 353,211 and Akure north population at 131,587 respectively (NPC, 2007).

The increase in landmass and population is evident in economic activities including daily trade in commodities carried out in a network of traditional and modern markets, service industries, government establishments, hotels and guest houses, which dotted the landscape of both inner and outskirts of the city. These activities have equally increased the number of traffic and travel volume in the city as people travel between their homes and different land uses.

In addition, the city being strategically located in the heart of the State is linked by fairly good roads to all other local government areas which generate considerably daily road traffic into the city. These intra-city and inter-state journeys are largely responsible for the peak traffic flow and congestion in the city. Space demand to park vehicles at places of destination is therefore high with almost all the commercial and business centres located within the city without designated parking areas. Consequently, vehicles are usually parked indiscriminately along the roads creating traffic obstruction and travel delays.

\section{Method of Study}

Using field observation, twelve congestion spots were identified in the study area, (Fig. I) especially during peak hours between $7 \mathrm{am}-10 \mathrm{am}$ when people are going to work, and between $4 \mathrm{pm}-7 \mathrm{pm}$ when they are returning to their homes.

Primary source of data was used through administration of questionnaires. The questions covered include distance covered from residence to work place or point of interview, experience of traffic hold-ups, period of experiencing traffic hold-up, time lost to traffic hold-up to and from a journey, as well as factors causing traffic congestion in the study area. A total of 540 copies of the questionnaires were administered out of which 500 , which is $92.5 \%$ of the total were properly filled and used for analysis. The result was however analysed using both descriptive and inferential statistics. Relevant materials and data were also sourced from published and unpublished official records, articles and others. 


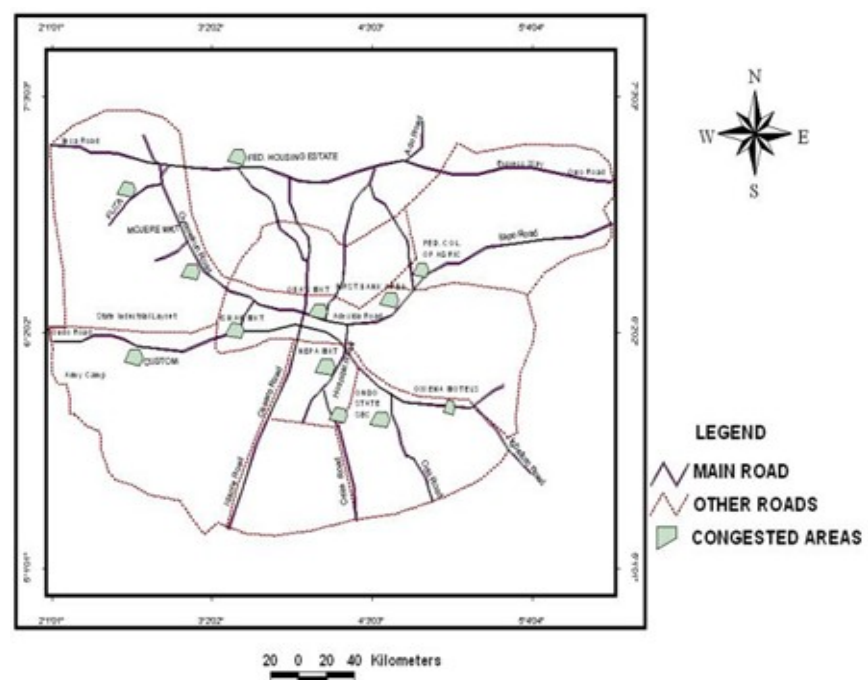

Figure 1: Akure showing Congested Areas Source: Ondo State Ministry of Lands and Housing, Akure and Author's Field Survey (2011)

\subsection{Mode of Transport}

\section{Analysis and Discussion of Findings}

The findings revealed that different modes of transport are available to urban commuters in Akure metropolis. These include trekking, tricycle, motorcycle, cabs/taxis, buses and private cars. Table 1 revealed that $23.4 \%$ of the residents indicated that they patronized motorcycles more frequently for their day to day transactions. $39.6 \%$ claimed they travel mostly by their personal cars. An approximately $10.4 \%$ and $26.6 \%$ of the sampled populations depend on Para-transit buses and taxis for intra city movements. The use of buses for public transport services in Akure metropolis is inadequate. Buses ply only few areas in the city such as the central market (Oja-oba) to Oda road, Igbatoro, Oke-aro, Danjuma, and FUTA. This is also similar to other cities in Nigeria where the use of buses are inadequate compared to cabs/taxis. This is a display of threshold population needed to sustain the use of buses which most rapidly developing capital towns lack. However, in some of the advanced countries, buses of different categories are designed to convey large number of passengers from one place to another.

Table 1: Most Accessible Mode of Transport

\begin{tabular}{|l|l|l|l|}
\hline S/N & Mode & Frequency & \% of the Total \\
\hline 01 & Motorcycle & 117 & 23.4 \\
\hline 02 & Private cars & 198 & 39.6 \\
\hline 03 & Bus & 52 & 10.4 \\
\hline 04 & Cab/taxi & 133 & 26.6 \\
\hline & TOTAL & $\mathbf{5 0 0}$ & $\mathbf{1 0 0 . 0}$ \\
\hline
\end{tabular}

Source: Author's Computation, 2012

\subsection{Travel Distance}

Information regarding distance covered by respondents from their residence to place of work or point of destination within the city is as shown in Table 2 . About $21 \%$ of the respondents covered less than $5 \mathrm{kms}$ while $57.4 \%$ travelled between $5-9 \mathrm{kms}$ from their residence to work place. Only $18.2 \%$ travelled between $10-$ $14 \mathrm{kms}$ and $2.4 \%$ claimed to travel between $15-19 \mathrm{kms}$ to their work place. It could be observed that respondents emerged from different distances and converge in activity centres within the city, which otherwise have turned to congestion spots. The centre of city, however as described by Blumefield (1961) is characterized by separation of places of residences from places of work which need efficient transport system.

Table 2: Travel Distance in the Study Area

\begin{tabular}{|l|c|l|c|}
\hline S/N & Distance Covered & Frequency & \% of the Total \\
\hline 01 & $<5 \mathrm{kms}$ & 104 & 20.8 \\
\hline 02 & $5-9 \mathrm{kms}$ & 287 & 57.4 \\
\hline 03 & $10-14 \mathrm{kms}$ & 91 & 18.2 \\
\hline 04 & $15-19 \mathrm{kms}$ & 12 & 2.4 \\
\hline 05 & $>19 \mathrm{kms}$ & 06 & 1.2 \\
\hline & TOTAL & $\mathbf{5 0 0}$ & $\mathbf{1 0 0 . 0}$ \\
\hline
\end{tabular}

Source: Author's Computation, 2012 


\subsection{Traffic Hold-up and Time Loss on Akure Roads}

The fact that about $80 \%$ of the respondents travelled more than $5 \mathrm{kms}$ from their residence as shown in Table 2, shows that the provision of urban transport has enable people to live further and further from their places of work and at the same time increase spatial distribution and diffusion of goods, services, and ideas in the Nigerian urban space. It was in the light of this that respondents were asked if they experience traffic holdup or not. However, $422(84.4 \%)$ of the respondents experience traffic hold-ups while only $78(15.6 \%)$ said they do not experience traffic hold-up. The traffic situation as observed in Akure also confirms what Ogunsanya (2002) observed that the most visible problem that affect everybody in many Nigerian urban centres today is that of traffic delays and congestion problems. This situation, he attributed to the astronomical increase in the volume of vehicles plying intra-urban roads in recent years, coupled with the fact that urban mass transit which would have reduced the use of personal cars remained relatively undeveloped.

Since 422 (84.4\%) of the respondents claimed to experience traffic hold-up, time lost as a result of this was sought from them. The result shows that time lost varies between 15 minutes to above 1 hour especially at the peak hours of $7 \mathrm{am}-10 \mathrm{am}$ when people are going to work and between $4 \mathrm{pm}-7 \mathrm{pm}$ when they journeyed back home. The summary of time lost to traffic hold-up is shown in Table 3.

Table 3: Time Lost to Traffic Hold-up

\begin{tabular}{|l|l|l|l|}
\hline S/N & Time Lost & Frequency & \% of the Total \\
\hline 01 & $<15 \mathrm{mins}$ & 50 & 11.8 \\
\hline 02 & $16-30 \mathrm{mins}$ & 80 & 19.0 \\
\hline 03 & $31-45 \mathrm{mins}$ & 105 & 24.9 \\
\hline 04 & $46-60 \mathrm{mins}$ & 125 & 29.6 \\
\hline 05 & $>60 \mathrm{mins}$ & 62 & 14.7 \\
\hline & TOTAL & $\mathbf{4 2 2}$ & $\mathbf{1 0 0 . 0}$ \\
\hline
\end{tabular}

Source: Author's Computation, 2012

From Table 3, about $12 \%$ of the respondents claimed they lost less than 15 minutes to hold-up while $19 \%$ lost between $16-30$ minutes in their course of journey within the city. However, more than $69 \%$ of the respondents lost more than 30 minutes to hold-up. It is of note therefore, that mobility and access are important factors influencing the success of most urban economic activities, but as noted by Ogundare (2013), the time lost due to traffic hold-ups span over some fundamental social and psychological costs. Apart from the direct increase in operational and maintenance costs of all vehicles on the road, it also leads to excessive tension and anxiety, irritation and cutbacks on working periods of man.

\subsection{Peak Period Travel}

Traffic hold-up is a peculiar problem in Akure metropolis, thus the need to examine the time of the day when respondents experience such hold-ups. Out of the 422 respondents that signified that they experience traffic hold-ups, about 24\% (101) said they use to experience traffic hold in the morning between 8.00am and $10.00 \mathrm{am}$ while $13.5 \%$ (57) of these respondents experience hold-up between $10.00 \mathrm{am}$ and $12.00 \mathrm{pm}$ (Table 4). About $46 \%$ (193) of the respondents experience traffic hold-ups between $2.00 \mathrm{pm}$ and $6.00 \mathrm{pm}$. The foregoing observation shows that two peak periods of traffic hold-ups are observable in the area, the first when respondents are going to their work place while the second when residents are returning home after the day's work. However as low as $16.8 \%$ (71) of the respondents said they use to experience traffic hold-ups between $12.00 \mathrm{pm}$ and $2.00 \mathrm{pm}$. This could be those that have completed their business for the day. The $8.5 \%$ (35) increase in the number of respondents that use to experience traffic hold-ups in the evening over that of morning peak period could be attributed to the number of teachers and students who left home early in the morning and returning home at this period. This condition is further aggravated by inadequate traffic control at intersection points by traffic wardens. The condition can also be attributed to indiscipline among drivers as well as bad stopping habits of minibus drivers to pick up and drop passengers at virtually on any part of the road cum double parking habits of private car owners.

Table 4: Period of Experiencing Traffic Hold-ups

\begin{tabular}{|l|l|l|l|}
\hline S/N & Occurrence of Traffic Hold-ups & Frequency & \% of the Total \\
\hline 01 & Btw $8.00-10.00 \mathrm{am}$ & 101 & 24.0 \\
\hline 02 & Btw $10.00-12.00 \mathrm{pm}$ & 057 & 13.5 \\
\hline 03 & Btw $12.00-2.00 \mathrm{pm}$ & 071 & 16.8 \\
\hline 04 & Btw $2.00-4.00 \mathrm{pm}$ & 090 & 21.3 \\
\hline 05 & Btw $4.00-6.00 \mathrm{pm}$ & 103 & 24.4 \\
\hline & Total & $\mathbf{4 2 2}$ & $\mathbf{1 0 0 . 0}$ \\
\hline
\end{tabular}

Source: Author's Computation, 2012 


\subsection{Factors Causing Traffic Congestion in Akure}

Population increase influence economic activities that dotted the landscape of any city. Both inner and outskirt of a city like Akure is linked together by roads. This not only increase the number of traffic and travel volume in the area as people travel between their homes and jobs, get services, shops and conduct businesses, but has led to heavy traffic on the roads. There are some factors which contribute to traffic congestion in Akure, and the varied notions of respondents are shown in Table 5.

Table 5: Factors causing Traffic Congestion in Akure

\begin{tabular}{|l|l|l|l|}
\hline S/N & Factors & Frequency & \% of the Total \\
\hline 01 & Inadequate parking spaces & 227 & 53.7 \\
\hline 02 & Un-coordinated traffic control & 83 & 19.7 \\
\hline 03 & Delays at road junctions & 64 & 15.2 \\
\hline 04 & Narrow or poor road conditions & 48 & 11.4 \\
\hline & Total & $\mathbf{4 2 2}$ & $\mathbf{1 0 0 . 0}$ \\
\hline
\end{tabular}

Source: Author's Computation, 2012

From the Table 5, 227 respondents about $53.7 \%$ claimed that inadequate parking spaces is the major factor causing traffic congestion in the study area while $83(19.7 \%)$ respondents claimed that un-coordinated traffic control is the major cause of traffic congestion. However, $64(15.2 \%)$ respondents were of the view that delays at road junctions and $48(11.4 \%)$ consider narrow or poor road conditions as the major factor of traffic congestion in the study area. Moreover other factors suggested by respondents to cause traffic congestion include street trading, market areas, flooded zones, point of accidents, waste dump sites, loading and off-loading by commercial vehicles, increase in the use of private vehicles, and jumat services especially during Friday service.

\subsection{Regression Equation established for the study}

In order to determine multiple regression model for the study, a regression model was developed using time lost due to traffic congestion (Table 3 ) as dependent variable (y) and factors causing traffic congestion in Akure as independent variables $\left(\mathrm{x}_{1}, \mathrm{x}_{2}, \mathrm{x}_{3}\right.$, and $\left.\mathrm{x}_{4}\right)$ to determine level of contribution of these factors in the equation. The summary of the result is shown in Table 6 below:

Table 6: Summary of Multiple Regression Result

\begin{tabular}{|l|l|l|l|}
\hline Variables & \multicolumn{3}{|l|}{ Un-standardised coefficients } \\
\cline { 2 - 4 } & Model & B & Standard Error \\
\hline \multirow{2}{*}{$\begin{array}{l}\text { Loss of travelling time } \\
\text { and factors causing } \\
\text { traffic congestion in }\end{array}$} & Constant & $\mathbf{6 . 1 4 1}$ & $\mathbf{0 . 0 0}$ \\
\cline { 2 - 4 } Akure. & IPSL & -1.632 & $\mathbf{0 . 0 0}$ \\
\cline { 2 - 4 } & NPRL & $-\mathbf{0 . 3 2 7}$ & $\mathbf{0 . 0 0}$ \\
\cline { 2 - 4 } & UCTL & $-\mathbf{0 . 3 2 4}$ & $\mathbf{0 . 0 0}$ \\
\cline { 2 - 4 } & DRJL & $-\mathbf{0 . 2 2 8}$ & $\mathbf{0 . 0 0}$ \\
\hline
\end{tabular}

Source: Computer Output

As indicated in Table 6, the multiple regression analysis between lost of travelling time (y) and factors causing traffic congestion in Akure $\left(\mathrm{X}_{1}, \mathrm{X}_{2}, \mathrm{X}_{3}\right.$, and $\left.\mathrm{X}_{4}\right)$ gives the equation:

LOTT $=6.141-1.632$ IPSL $-0.327 \mathrm{NPRL}-0.324 \mathrm{UCTL}-0.228 \mathrm{DRJL}$

Where LOTT $=$ Loss of Travel Time (the Dependent variable), while the independent variables are:

IPSL $=$ Inadequate Parking Spaces $\left(\mathrm{X}_{1}\right)$

NPRL $=$ Narrow or Poor Road Conditions $\left(\mathrm{X}_{2}\right)$

$\mathrm{UCTL}=$ Uncoordinated Traffic Control $\left(\mathrm{X}_{3}\right)$

$\mathrm{DRJL}=$ Delays at Road Junctions $\left(\mathrm{X}_{4}\right)$

The above equation implies that there is a negative or inverse relationship between loss of travelling time in $(\mathrm{y})$ and factors $\left(\mathrm{X}_{1}, \mathrm{X} 2, \mathrm{X}_{3}\right.$, and $\left.\mathrm{X}_{4}\right)$ causing traffic congestion in Akure. However, as revealed in the study, if there is no traffic congestion in Akure, time lost due to traffic congestion will be 6 minutes, but a unit improvement in each of the factors causing traffic congestion in Akure implies that time lost due to traffic congestion will be 4 minutes. Twice the improvement in each of the factors implies that only a minute will be lost to traffic congestion, while thrice the improvement in each of the factors implies zero or no time lost to traffic congestion and traffic congestion will be totally eliminated.

On the other hand, if there is a unit decrease in each of the factors causing traffic congestion, time lost to traffic congestion will be 8 minutes while two units of decrease in each of the factors will lead to 11 minutes loss. Moreover, thrice the unit of decrease in each of the factors implies 13 minutes loss to traffic congestion and so on and so forth. 
However, as revealed in the findings and as observed in the findings of Chandra et al (2002) and Atubi and Onokala (2004a and 2004b) that in Nigeria as elsewhere, traffic congestions are caused by inadequate parking spaces. Therefore, all other factors causing traffic congestion in Akure except inadequate parking spaces are assumed to be insignificant and tend to zero. Thus, the model of time loss due to traffic congestion in Akure can now be written in the form of:

LOTT $=6.141-1.632$ IPSL, where IPSL $=$ Inadequate Parking Spaces.

The implication of the above model is that, if there is no adequate parking facilities, time loss to traffic congestion in Akure will be 6 minutes and this decrease to about four and half minutes with a unit increase (positive one) inadequacy of parking spaces and about 3 minutes with a two unit increase (positive two) inadequacy of parking spaces and eventually to zero with a 4 unit increase (positive four) inadequacy of parking spaces.

\section{Conclusion and Planning Implications of the Study}

The study has empirically established parking in the urban core of Akure as a major difficulty for traffic congestion. Congestion is one of the most prevalent transport problems in large urban agglomerations. Traffic flows along the major roads in the city need to be monitored regularly as well as provision of off-street parking facilities in designated areas of the city. Lack of off-street parking facilities result in on-street parking, which reduces the effective width of roads leading to obstruction of traffic flow. Off-street parking spaces should be provided especially along those roads where there are concentrations of activities. The study also encourages mass transportation services and creation of more bus stops along the roads.

\section{References}

[1]. Aribigbola, A. and Osunsanmi, G.O. (2010). Family Life Cycle Model and Urban Housing Choice in Developing Countries: Empirical Validation from Akure, Nigeria. The Social and Management Scientists 4(1) $17-27$.

[2]. Atubi, A.O. and Onokala, P.C. (2004a). The Road Network Characteristics on Traffic Flow in South western Nigeria: A Case Study of Warri Metropolis. Journal of The Social and Management Sciences Review, 1(1): 102 - 113.

[3]. Atubi, A.O. and Onokala, P.C. (2004b). The Accessibility of Centres to the Road Networks: The Case of Lagos Island, Nigeria. Journal of Ecology and Environmental Dynamics, 2: 140 - 151.

[4]. Blumfield, Hans. (1961). Transportation in the Modern Metropolis. Queens Quarterly, Vol. LXVII, No. 4, Winter 1961.

[5]. Chandra, B., Kara, H., Hani, K., Qinglin, M., and Lisa, W. (2002). Development of an Urban Accessibility Index: Literature Review, Research Report, No. 2-49388-1. Centre for Transport Research: The University of Texas, Austin.

[6]. Mrakpor, O.O. (1986). Public Passenger Transport in Benin City: A study of Accessibility and Reliability,Unpublished M.Sc Thesis in the Dept. of Geography and Regional Planning, University of Benin, Benin City.

[7]. N.P.C. (2007). Census' 2006 National Summary. National Population Commission.

[8]. Ogunbodede, E.F. (1990). Adequacy of Public Transport Services in Akure Metropolis: A Geographical Analysis. M.Sc Thesis submitted to the Department of Geography and Planning Sciences, University of Benin, Benin City, Nigeria

[9]. Ogunbodede, E.F. (2004). Urban Transport and Environment, in I. Vandu- chikolo et al (eds), Perspectives on Urban Transportation in Nigeria, Zaria: Nigerian Institute of Transport Technology, Zaria pp 101-120.

[10]. Ogunbodede, E.F. (2006). Basic Statistics for Social and Management Sciences. Pamma Press,Vol. 2.

[11]. Ogunbodede, E.F. (2008). Urban Road Transportation in Nigeria from 1960 - 2006: Problems, Prospects and Challenges. Ethiopian Journal of Environmental Studies and Management, 1 (1): $145-164$.

[12]. Ogunbodede, E.F., Olurankinse, F. and Ilesanmi, A.O. (2008). Luxurious Buses as a Means of Night Journey in Nigeria: Challenges and Implications for Transportation Planning. Ethiopian Journal of Environmental Studies and Management, 1 (3) 52 - 62.

[13]. Ogundare, B.A. (2013). A Geographical Analysis of Parking Facilities in Akure, Ondo State. Unpublished M.Sc Thesis, Department of Geography and Planning Sciences, Adekunle Ajasin University, Akungba Akoko, Nigeria.

[14]. Ogunjumo, A. (1986). The Pattern of Trip Generation at Ile-Ife. Journal of Nigerian Institute of Town Planners, Vi (vii) pp 99 114.

[15]. Ogunsanya, A.A. (1998). Moving the Urban Masses: Two Steps Forward One Step Backward, in M. Dange; Van-Chikolo, I. and Ogunsanya, A.A. (ed) Issues in Transport Planning and Management, NITT, Nigeria.

[16]. Ogunsanya, A.A. (2002). Maker and Breaker of Cities. 59 $9^{\text {th }}$ Inaugural Lecture Presented at The University of Ilorin, Nigeria, on $27^{\text {th }}$ June, 2002.

[17]. Rodrigue, J.P. (2011). Urban Transport Problems. Department of Global Studies and Geography, Hofsta University.

[18]. Traffic Control (2012). Encyclopaedia Britannica. Encyclopaedia Britannica Ultimate Reference Suite. Chicago: Encyclopaedia Britannica. 